\title{
Right Heart Catheterization
}

National Cancer Institute

\section{Source}

National Cancer Institute. Right Heart Catheterization. NCI Thesaurus. Code C80411.

A diagnostic procedure in which a catheter is guided into the right heart, where pressures

may be measured and radiocontrast material may be injected to visualize blood flow in and around the right heart. 